\title{
A comparative analysis on the in vivo toxicity of copper nanoparticles in three species of freshwater fish
}

\author{
Lan Song ${ }^{\mathrm{a}, *}$, Martina G. Vijver ${ }^{\mathrm{a}}$, Willie J.G.M. Peijnenburg ${ }^{\mathrm{a}, \mathrm{b}}$, Tamara S. Galloway ${ }^{\mathrm{c}}$, Charles R. Tyler $^{\mathrm{c}}$ \\ ${ }^{a}$ Institute of Environmental Sciences (CML), University Leiden, Leiden, The Netherlands \\ ${ }^{\mathrm{b}}$ National Institute for Public Health and the Environment, Bilthoven, The Netherlands \\ ${ }^{\mathrm{c}}$ Biosciences, College of Life and Environmental Sciences, University of Exeter, United Kingdom
}

\section{H I G H L I G H T S}

- Comparative in vivo toxicity of nano-copper was studied in three fish species.

- Temperature can significantly affect the fate and toxicity of nano-copper in water.

- Copper ions were the main driver for the toxic effect of nano-copper.

- Nano-copper can cause damage to gill filaments and gill pavement cells.

- Physiological differences affect the sensitivity of fish species to nano-copper.

\section{A R T I C L E I N F O}

\section{Article history:}

Received 2 January 2015

Received in revised form 2 May 2015

Accepted 8 June 2015

Available online 26 June 2015

\section{Keywords:}

Copper

Nanoparticle

In vivo

Toxicity

Histology

\begin{abstract}
A B S T R A C T
Copper nanoparticles (CuNPs) are used extensively in a wide range of products and the potential for toxicological impacts in the aquatic environment is of high concern. In this study, the fate and the acute toxicity of spherical $50 \mathrm{~nm}$ copper nanoparticles was assessed in juvenile rainbow trout (Oncorhynchus mykiss), fathead minnow (Pimephales promelas) and zebrafish (Danio rerio) for in vivo aqueous exposures following standardized OECD 203 guideline tests. The fate of the CuNPs in the aqueous media was temperature dependent. At the higher study temperature $\left(26 \pm 1{ }^{\circ} \mathrm{C}\right)$, there was both an enhanced particle aggregation and higher rate of dissolution compared with that at the lower study temperature $\left(15 \pm 1^{\circ} \mathrm{C}\right) .96 \mathrm{~h} \mathrm{LC} 50 \mathrm{~S}$ of the CuNPs were $0.68 \pm 0.15,0.28 \pm 0.04$ and $0.22 \pm 0.08 \mathrm{mg} \mathrm{Cu} / \mathrm{L}$ for rainbow trout, fathead minnow and zebrafish, respectively. The $96 \mathrm{~h}$ lowest-observed-effect concentration (LOEC) for the CuNPs were $0.17,0.023$ and $<0.023 \mathrm{mg} / \mathrm{L}$ for rainbow trout, fathead minnow, and zebrafish respectively, and are below the predicted environmental concentration of CuNPs for some aquatic environments suggesting a possible ecotoxicological risk to fish. Soluble copper was one of main drivers for the acute toxicity of the copper nanoparticles suspensions. Both CuNPs suspension and copper nitrate caused damage to gill filaments and gill pavement cells, with differences in sensitivity for these effects between the fish species studied. We show therefore common toxicological effects of CuNPs in different fish species but with differences in sensitivity with implications for hazard extrapolation between fish species.
\end{abstract}

(c) 2015 Elsevier Ltd. All rights reserved.

\section{Introduction}

The potential toxicological impacts of nanoparticles (NPs) are of high concern due to the widespread application and high reactivity of NPs. One type of nanoparticle of particular concern is copper nanoparticles (CuNPs). CuNPs are applied widely in various products, including in electronics, metallic inks and textiles, because

\footnotetext{
* Corresponding author.

E-mail address: song@cml.leidenuniv.nl (L. Song).
}

of their optical, electrical, and catalytic properties (Han et al., 2011; Hatamie et al., 2014; Kida et al., 2007; Kim et al., 2011; Kubota et al., 2014; Lee et al., 2014; Li et al., 2014). The predicted environmental concentration of CuNPs in some receiving waters is $0.06 \mathrm{mg} \mathrm{Cu} / \mathrm{L}$, with a $95 \%$ confidence interval of $0.01-0.92 \mathrm{mg} \mathrm{Cu} / \mathrm{L}$ (Chio et al., 2012) and this has raised concern on their potential for adverse effects on aquatic organisms (Chen et al., 2014; Ganesh et al., 2010).

Some metallic NPs readily undergo dissolution and aggregation in the aquatic environment (Lowry et al., 2012). Dissolution of 
CuNPs produces copper ions, which are highly toxic to fish (Black et al., 2015; Kong et al., 2013). The aggregates of CuNPs may also cause adverse effect to fish because they can remain in a nanostructured form and thus more highly reactive (Griffitt et al., 2009; Zhao et al., 2011). Studies have shown that rates of dissolution and aggregation of metallic NPs can vary considerably under different environment conditions (Handy et al., 2008). For instance, lowering $\mathrm{pH}$ can significantly increase the amount of ion release from metallic NPs (Baalousha et al., 2008) and the presence of organic matter may affect the aggregation size of metallic NPs (Grillo et al., 2015). This illustrates the importance of considering the fate of metallic NPs in studies investigating their toxicity.

Studies conducted to date have reported adverse effects of CuNPs in diverse fish species at sub-lethal levels. For example, exposure to CuNPs via aqueous has been shown to affect the gill filament structure in rainbow trout (Oncorhynchus mykiss; $80 \mathrm{~nm}$ particles exposed at $0.25 \mathrm{mg} / \mathrm{L}$; Griffitt et al., 2007), and induce tissues oxidative stress in the liver, gills and muscles of juvenile Epinephelus coioides after 25 days exposure to CuNPs via aqueous with a mean primary particle diameter of $85 \pm 29 \mathrm{~nm}$ (Wang et al., 2014). A further study on juvenile rainbow trout found that CuNPs (mean primary particle size of $87 \pm 27 \mathrm{~nm}$ ) induced similar types of pathologies in gill, gut, liver, kidney, brain and muscle as occurs for copper ions (Al-Bairuty et al., 2013). Little is known however on the comparative sensitivity of different fish species to the effects of CuNPs. Making comparisons between species for effects across different studies is complicated by the fact that the studies published have used different particles, exposure conditions, and effect measures. Furthermore, as the dissolution profile of CuNPs were not investigated in many of the studies reported in the literature (Al-Bairuty et al., 2013; Wang et al., 2014), it is still unclear whether the toxicity of CuNPs suspensions in fish species was attributed to the particles in the CuNPs suspensions or the copper ions released from CuNPs.

Here we evaluate the fate CuNPs (50 nm spherical) in the test medium and their comparative acute toxicity in three fish species (rainbow trout, fathead minnow and zebrafish) exposed via water by adopting OECD 203 test guidelines for supporting risk assessment of this material. The study both compares the sensitivities of different fish species to CuNPs suspension over time and investigates the contribution of particles and ions to the toxicity of CuNPs suspension. Histopathology was undertaken to examine for effects of the CuNPs suspension and copper ions (via exposure to copper nitrate) on the gill structure in the different fish species.

\section{Materials and methods}

\subsection{Experimental set up}

$50 \mathrm{~nm}$ CuNPs powder stored in inert gas was purchased from IoLiTec, Inc. (Germany). The CuNPs suspension was freshly prepared by dispersing the CuNPs powder in standardized synthetic freshwater and sonicated for $10 \mathrm{~min}$ with a probe sonicator (Cole Parmer CPX 130 ultrasonic processor). The standardized synthetic freshwater consisted of $58 \mathrm{mg} / \mathrm{L} \quad \mathrm{CaCl}_{2} \cdot 2 \mathrm{H}_{2} \mathrm{O}, 24.65 \mathrm{mg} / \mathrm{L}$ $\mathrm{MgSO}_{4} \cdot 7 \mathrm{H}_{2} \mathrm{O}, 12.95 \mathrm{mg} / \mathrm{L} \mathrm{NaHCO}_{3}, 1.15 \mathrm{mg} / \mathrm{L} \mathrm{KCl}$ and $12.5 \mathrm{mg} / \mathrm{L}$ Tropic Marin Sea Salt with a final conductivity of $350 \mathrm{mS}$ and a $\mathrm{pH}$ of 7.2-7.4, which is within acceptance of the U.S. EPA guidelines (EPA, 1986; Paull et al., 2008).

The exposure studies were carried out according to the OECD guideline 203 (OECD, 1992). Juvenile zebrafish (length: $26.9 \pm 2.1 \mathrm{~mm}$, weight: $0.17 \pm 0.03 \mathrm{~g}$ ), juvenile fathead minnow (length: $56.0 \pm 7.4 \mathrm{~mm}$, weight: $1.80 \pm 0.66 \mathrm{~g}$ ) and juvenile rainbow trout (length: $123 \pm 13 \mathrm{~mm}$, weight: $20.3 \pm 4.5 \mathrm{~g}$ ) were used for the exposures. Zebrafish and fathead minnow belong to the family of Cyprinidae. Rainbow trout belongs to the family of Salmonidae. The fish species were obtained from a local supplier in the UK and tests were carried out in $30 \mathrm{~L}$ tanks (Rainbow trout) and $15 \mathrm{~L}$ tanks (Zebrafish and fathead minnow) in reconstituted fresh water that were well aerated. Six fish were randomly placed into the exposure tanks. The dosing adopted for each fish species was based on pilot experiments that determined the toxicity for CuNPs suspension in the different study species. The final exposure concentrations of the CuNPs suspension were $0,0.05,0.01,0.3,0.5$ and $1 \mathrm{mg} \mathrm{Cu} / \mathrm{L}$ for rainbow trout, and $0,0.03,0.05,0.01,0.3$ and $0.5 \mathrm{mg} \mathrm{Cu} / \mathrm{L}$ for fathead minnow and zebrafish. The final exposure concentration of $\mathrm{Cu}\left(\mathrm{NO}_{3}\right)_{2}$ were $0,0.05,0.1,0.2,0.4$ and $0.6 \mathrm{mg}$ $\mathrm{Cu} / \mathrm{L}$ for the rainbow trout exposure and $0,0.003,0.005,0.01$, 0.03 and $0.05 \mathrm{mg} \mathrm{Cu} / \mathrm{L}$ for fathead minnow and zebrafish exposures. The concentration-response curve of copper nitrate was used to assess to what extent the toxicity of the CuNPs could be accounted for by the copper ions that would derived from the NPs (more information can be found in the section of data analysis and statistics). Each exposure was carried out in duplicate tanks. Fish were maintained under a $12 \mathrm{~h}$ light: $12 \mathrm{~h}$ dark photoperiod. Exposures were conducted for $96 \mathrm{~h}$ in a semi-static system with the test media renewed thoroughly every $24 \mathrm{~h}$ to help maintain the stability of exposure concentrations. The system was aerated to maintain the dissolved oxygen level at a value of at least $90 \%$ of the air saturation value. The water temperature was maintained at $15 \pm 1{ }^{\circ} \mathrm{C}$ for rainbow trout and $26 \pm 1{ }^{\circ} \mathrm{C}$ for both zebrafish and fathead minnow. Fish mortalities were recorded at intervals of 24 , 48,72 and $96 \mathrm{~h}$ and any dead fish were removed from the exposure tanks at these times. Fish were not fed during the experiment.

\subsection{Physico-chemical characterization}

The CuNPs were characterized as dry powder using Transmission Electron Microscopy (TEM). The hydrodynamic diameter and zeta potential of the CuNPs suspension were measured for a suspension of $1 \mathrm{mg} \mathrm{Cu} / \mathrm{L}$ immediately after preparation $(0 \mathrm{~h})$, and after $24 \mathrm{~h}$ in the tank water under the different culture conditions $\left(15^{\circ} \mathrm{C}\right.$ and at $26^{\circ} \mathrm{C}$ ) by Dynamic Light Scattering (DLS) on a Zetasizer Nano-ZS instrument (Malvern, Instruments Ltd., UK). Three independent replicates were measured with each comprising of three separate measurements.

\subsection{Measured exposure concentrations and ion release}

The exposure concentrations were quantified using inductively coupled plasma-optical emission spectrometry (ICP-OES). Toxicity data were calculated based on measured exposure concentrations. In order to measure the ion release from the CuNPs under each culture scenario in the presence of fish, $15 \mathrm{~mL}$ CuNPs suspension was sampled from the middle of the water column after $24 \mathrm{~h}$ of incubation at temperatures of $15^{\circ} \mathrm{C}$ and $26^{\circ} \mathrm{C}$. The samples were subsequently centrifuged at $30,000 \mathrm{~g}$ for $20 \mathrm{~min}$ at $4{ }^{\circ} \mathrm{C}$ (Beckman Avanti J-25 centrifuge, UK) to remove the particles from the CuNPs suspension (Song et al., 2014). The supernatants were then acidified using $10 \% \mathrm{HNO}_{3}$ and then analyzed using ICP-OES. Copper ion release (\%) was calculated as percentage of the total copper concentration.

\subsection{Gill histology}

After the exposure, all remaining fish were anesthetized and killed rapidly by a schedule 1 method and according to UK Home Office regulations (Office, 1996), and the total body length and weight of the fish measured. To investigate for possible effects of the CuNPs suspension and $\mathrm{Cu}\left(\mathrm{NO}_{3}\right)_{2}$ on the gills, two fish from each of the controls, the highest concentration of the CuNPs suspension, 
and $\mathrm{Cu}\left(\mathrm{NO}_{3}\right)_{2}$ were collected and fixed in the appropriate manners for histological examination by light microscopy and Scanning Electron Microscopy (SEM) as described below. Examination of gill histology was conducted for rainbow trout and fathead minnow only as representatives of the two divergent families of fish studied (Salmonidae and Cyprinidae).

\subsubsection{Light microscopy}

The second gill arch from the right side of each fish for the treatments described above was dissected out and immediately fixed in bouin's fixative for $4 \mathrm{~h}$. The samples were then transferred to 70\% Industrial Methylated Spirit (IMS) and stored overnight. Samples were then dehydrated in graded series of ethanol $(70 \%, 80 \%, 90 \%$, $98 \%$ and $100 \%$ ), cleared in histoclear ${ }^{\circledR}$ and embedded in paraffin wax. Paraffin sections of $5 \mu \mathrm{m}$ in thickness were cut using a Leica rotatory microtome (AS325) and placed onto glass slides. Paraffin sections were then stained using haematoxylin and eosin and fixed for observation using light microscopy.

\subsubsection{Scanning Electron Microscopy (SEM)}

The third gill arch from the right side of each fish for the treatments was dissected out and immediately fixed in $3 \%$ Glutaraldehyde in $0.1 \mathrm{M}$ Cacodylate buffer ( $\mathrm{pH}$ 7.2) overnight. The samples were then washed twice with $0.1 \mathrm{M}$ Cacodylate buffer and fixed in $1 \%$ osmium tetroxide in $0.1 \mathrm{M}$ Cacodylate buffer for $2 \mathrm{~h}$. These samples were then washed three times using pure water and dehydrated in ascending grades of ethanol (30\%, $40 \%, 50 \%, 60 \%$, $70 \%, 80 \%, 90 \%$ and $100 \%$ ) for 10 min each. After storing overnight in $100 \%$ ethanol they were subject to critical point drying in carbon dioxide. The samples were subsequently sputter-coated with platinum and observed using JEOL JSM 6390LV scanning electron microscopy operating under $15 \mathrm{kV}$.

\subsection{Data analysis and statistics}

Concentration-response curves for the CuNPs suspension and $\mathrm{Cu}\left(\mathrm{NO}_{3}\right)_{2}$ were plotted. The median lethal concentration $\left(\mathrm{LC}_{50}\right)$ and the lowest-observed-effect concentration (LOECs) of the CuNPs suspension and $\mathrm{Cu}\left(\mathrm{NO}_{3}\right)_{2}$ after $96 \mathrm{~h}$ were calculated based on measured exposure concentrations using SPSS 16.0 (IBM SPSS, Armonk, NY, USA). Statistical significance $(p<0.05)$ of the $\mathrm{LC}_{50}$ of the CuNPs suspension or the $\mathrm{Cu}\left(\mathrm{NO}_{3}\right)_{2}$ solutions were compared between the different time points for each fish species using One-way ANOVA.

To better understand the contribution of soluble copper ions to the overall toxicity of the CuNPs suspension, the average ion content at each exposure concentration of CuNPs (at $24 \mathrm{~h}$ ) was used to calculate the toxicity caused by copper ions in the CuNPs suspension according to the concentration-response curve of $\mathrm{Cu}\left(\mathrm{NO}_{3}\right)_{2}$, as described previously (Song et al., 2014). Briefly, it was assumed that there are no interactions between the particles and copper ions. The test water was renewed every $24 \mathrm{~h}$ to help maintain the stability of exposure concentrations and the average ion concentration at each exposure concentration of CuNPs at $24 \mathrm{~h}$ was used to calculated the toxicity caused by copper ions in the CuNPs suspension according to the concentration-response curve of $\mathrm{Cu}\left(\mathrm{NO}_{3}\right)_{2}$. As the total toxicity of copper suspensions was assessed experimentally, the toxic effect of the particle form of the CuNPs can be deduced from the total toxicity of copper suspensions using the response addition model (Backhaus et al., 2000):

$E_{\text {particles }}=1-\left[\left(1-E_{\text {total }}\right) /\left(1-E_{\text {ions }}\right)\right]$

where $E_{\text {particles }}$ represents the toxicity caused by the particles in the CuNPs suspension.
$E_{\text {total }}$ represents the total toxicity caused by the CuNPs suspension, which was measured experimentally. $E_{\text {ions }}$ represents the toxicity caused by copper ions in the CuNPs suspension, which was calculated according to the concentration-response curve of $\mathrm{Cu}\left(\mathrm{NO}_{3}\right)_{2}$ using the average ion concentration at each exposure concentration of CuNPs at $24 \mathrm{~h}$.

\section{Results}

\subsection{Physiochemical properties and fate of the CuNPs}

TEM illustrates the spherical nature of the CuNPs as supplied as a dry powder (Fig. 1a). Temperature was found to affect the aggregation and dissolution processes of CuNPs in the testing water. DLS measurements showed that the majority of CuNPs aggregates had a hydrodynamic diameter of between $50 \mathrm{~nm}$ and $200 \mathrm{~nm}$ and approximately $62 \%$ of the CuNPs aggregates were smaller than $100 \mathrm{~nm}$ immediately after their dispersion at $15^{\circ} \mathrm{C}$ in testing water (Fig. 2). At $24 \mathrm{~h}$ in the trout water exposures (conducted at $15^{\circ} \mathrm{C}$ ), most of the CuNPs aggregates were distributed within the size range between $60 \mathrm{~nm}$ and $300 \mathrm{~nm}$, and only 29\% of the aggregates had a hydrodynamic diameter of less than $100 \mathrm{~nm}$ (Fig. 2). The hydrodynamic diameter of the CuNPs aggregates in the same water for the cyprinid fish exposures (conducted at $26^{\circ} \mathrm{C}$ ) were between $120 \mathrm{~nm}$ and $1000 \mathrm{~nm}$. Between 7\% and 15\% of the CuNPs was present as dissolved ions after a $24 \mathrm{~h}$ incubation in the tank water at $15^{\circ} \mathrm{C}$, while the percentage of ion release was considerably higher ( $25 \pm 3 \%$ ) in the cyprinid fish exposures (at a temperature of $26^{\circ} \mathrm{C}$; Fig. 1b). These findings suggest that a higher incubation temperature resulted in both a greater particle aggregation size and higher percentage of ion release of the CuNPs.

The zeta potential of the CuNPs suspension in the testing water was $-13 \pm 2.1 \mathrm{mV}$ and $-16.2 \pm 2.1 \mathrm{mV}$ immediately after its constitution at $15^{\circ} \mathrm{C}$ and $26{ }^{\circ} \mathrm{C}$, respectively (at $0 \mathrm{~h}$, Fig. 1c) and between $-22.8 \pm 4.2 \mathrm{mV}$ and $-20.2 \pm 4.7 \mathrm{mV}$ after $24 \mathrm{~h}$ exposure in the reconstituted water at $15{ }^{\circ} \mathrm{C}$ and $26^{\circ} \mathrm{C}$, respectively.

\subsection{Acute toxicity of the CuNPs suspension}

The exposure concentrations were measured (Supplementary Information 1) and used to estimate the $\mathrm{LC}_{50}$ values of CuNPs suspension and copper nitrate. The $\mathrm{LC}_{50}$ values of the CuNPs suspension decreased with exposure duration (Fig. 3). Mortality was induced in rainbow trout and zebrafish after $24 \mathrm{~h}$ with the LOEC of the CuNPs suspension of 0.51 and $0.30 \mathrm{mg} \mathrm{Cu} / \mathrm{L}$ for rainbow trout and zebrafish, respectively. No mortality was observed for fathead minnow after $24 \mathrm{~h}$ of incubation at the same concentrations (Supplementary Information 2). The toxicity of the CuNPs suspension increased sharply after $48 \mathrm{~h}$, with $\mathrm{LC}_{50}$ values of $0.99 \pm 0.15,0.47 \pm 0.02$ and $0.40 \pm 0.00 \mathrm{mg} \mathrm{Cu} / \mathrm{L}$ for rainbow trout, fathead minnow and zebrafish, respectively. After $72 \mathrm{~h}$, the $\mathrm{LC}_{50}$ values for rainbow trout, fathead minnow and zebrafish were $0.90 \pm 0.16,0.33 \pm 0.04$ and $0.25 \pm 0.04 \mathrm{mg} \mathrm{Cu} / \mathrm{L}$, respectively. For trout this value was not significantly different from the toxicity at $48 \mathrm{~h}$. The $\mathrm{LC}_{50}$ value for the CuNPs suspension in trout was $0.68 \pm 0.15 \mathrm{mg} \mathrm{Cu} / \mathrm{L}$ at $96 \mathrm{~h}$, which was significantly lower compared to the value at $72 \mathrm{~h}$ (Fig. 3a). There were no changes in the $\mathrm{LC}_{50}$ values for fathead minnow and zebrafish between $96 \mathrm{~h}$ and $72 \mathrm{~h}$. Compared with the CuNPs suspension, $\mathrm{Cu}\left(\mathrm{NO}_{3}\right)_{2}$ had a higher toxicity in all fish species at all the time points, with $96 \mathrm{~h} \mathrm{LC}_{50} \mathrm{~S}$ of $0.24 \pm 0.03,0.07 \pm 0.01,0.04 \pm 0.01 \mathrm{mg} \mathrm{Cu} / \mathrm{L}$ for rainbow trout, fathead minnow and zebrafish, respectively (Fig. 3). The $96 \mathrm{~h} \mathrm{LOECs}$ for the CuNPs suspension were 0.17 and $0.023 \mathrm{mg} \mathrm{Cu} / \mathrm{L}$ for rainbow trout and fathead minnow, respectively. The $96 \mathrm{~h}$ LOEC of the CuNPs suspension for zebrafish was below $0.023 \mathrm{mg} \mathrm{Cu} / \mathrm{L}$. The 


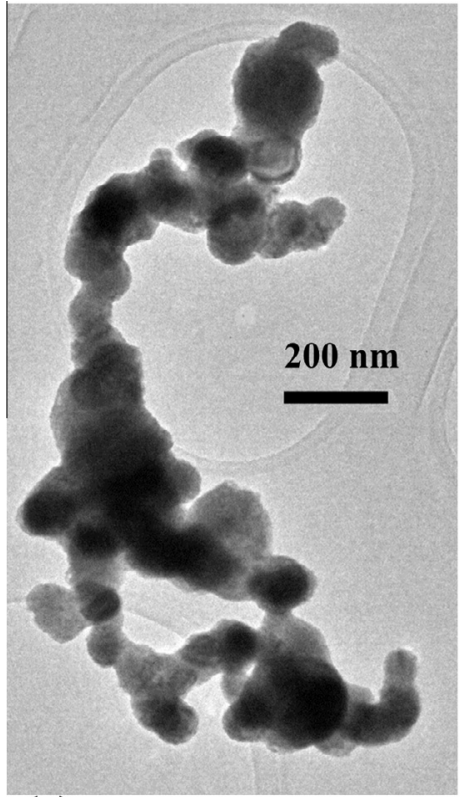

(a)
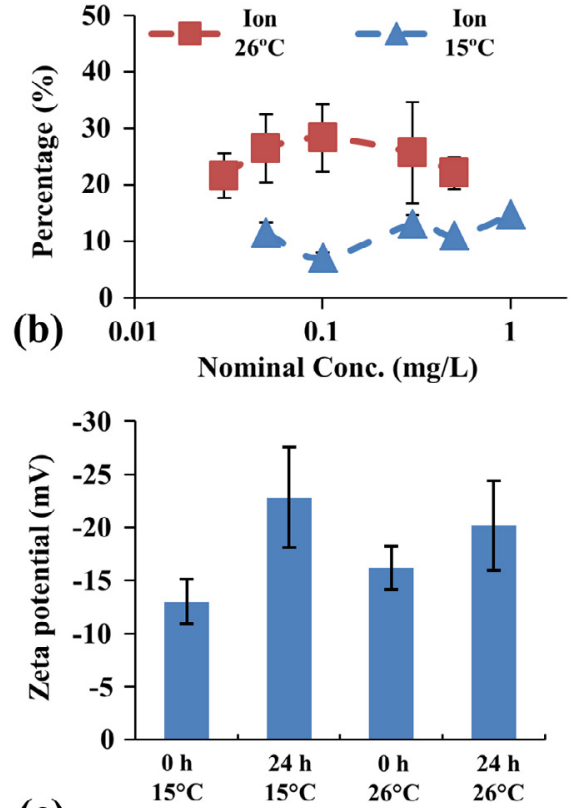

(c)

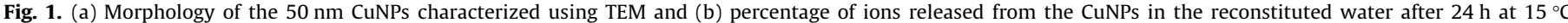

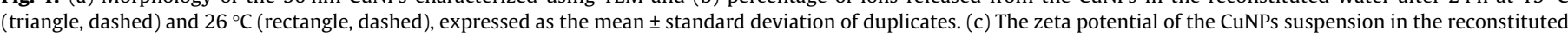
water at time $0 \mathrm{~h}$ and after $24 \mathrm{~h}$ at different temperatures $\left(15^{\circ} \mathrm{C}\right.$ and $26^{\circ} \mathrm{C}$ ), expressed as mean \pm standard deviation of triplicates.

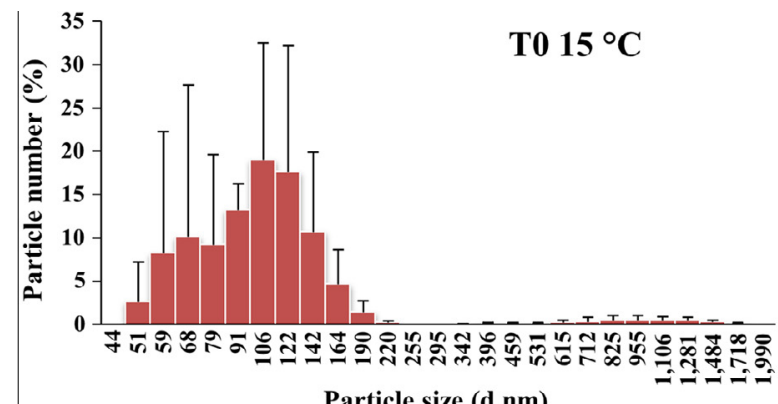

Particle size (d.nm)

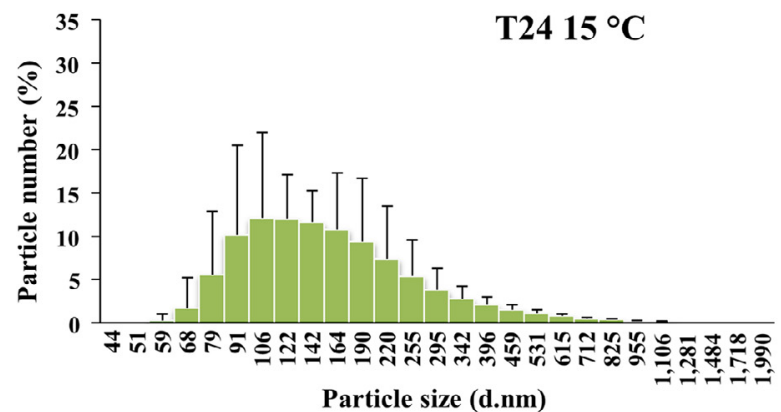

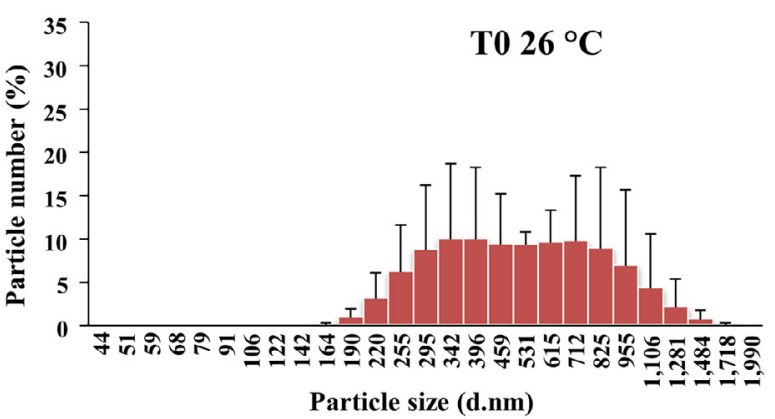

$\mathrm{T} 2426^{\circ} \mathrm{C}$

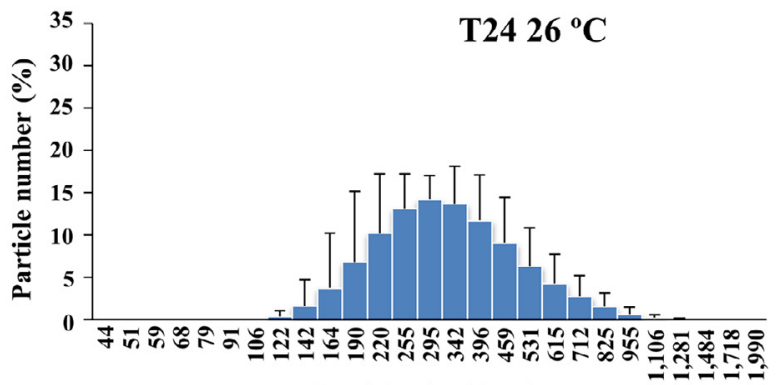

Particle size (d.nm)

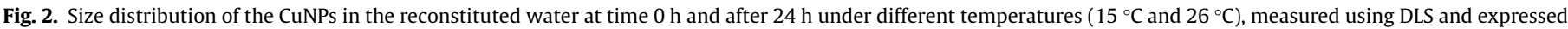
as the mean size $(\mathrm{nm}) \pm$ standard deviation of triplicates.

toxicity of the CuNPs suspension and copper nitrate varied between the different fish species and was higher for the zebrafish and fathead minnow compared with the rainbow trout (Supplementary Information 3).

Comparing the toxicity (induced mortality) caused by the CuNPs suspension, and their dissolution profiles in the different exposures, to the toxicity of soluble copper, it was established that soluble copper was a main driver for the toxicological effect caused by the CuNPs suspension (Fig. 4). A possible toxicological effect caused additionally by the particles in the CuNPs suspension was only observed only for the fathead minnow exposures (Fig. 4).

\subsection{Gill histology}

Histological sections of fish gills after 96 h exposure to the highest exposure concentration of the CuNPs suspension and $\mathrm{Cu}\left(\mathrm{NO}_{3}\right)_{2}$ are shown in Fig. 5. In rainbow trout after $96 \mathrm{~h}$ of exposure to $1 \mathrm{mg}$ $\mathrm{Cu} / \mathrm{L}$ and $0.5 \mathrm{mg} \mathrm{Cu} / \mathrm{L}$ induced alterations were observed in the gill 

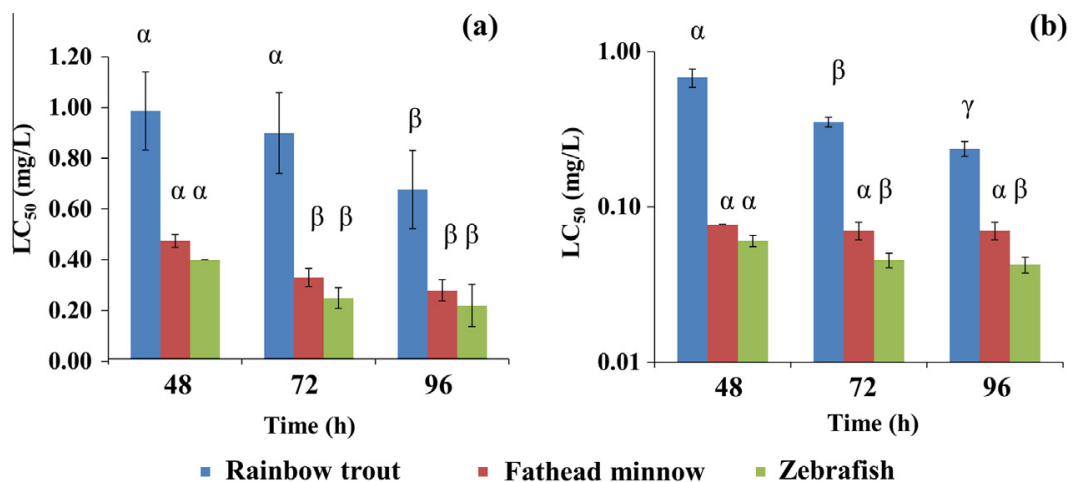

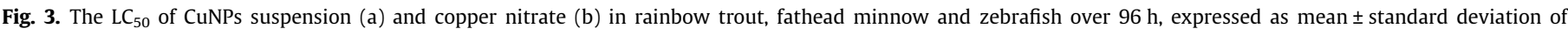

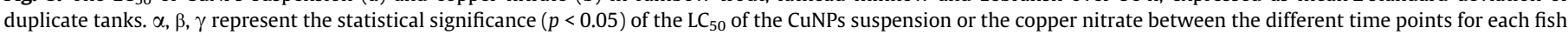
species. Note that toxicity data were log-transformed in case of copper nitrate.
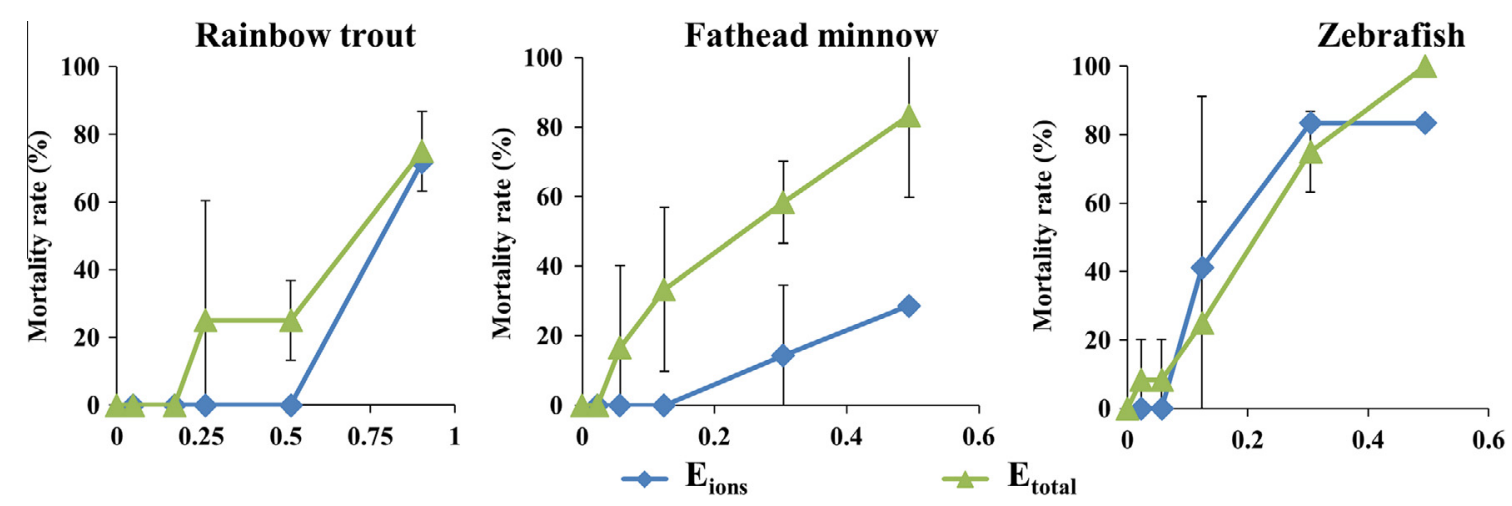

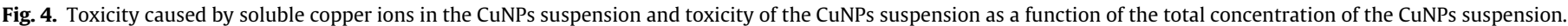
The results are expressed as mean \pm standard deviation of the two tank replicates.

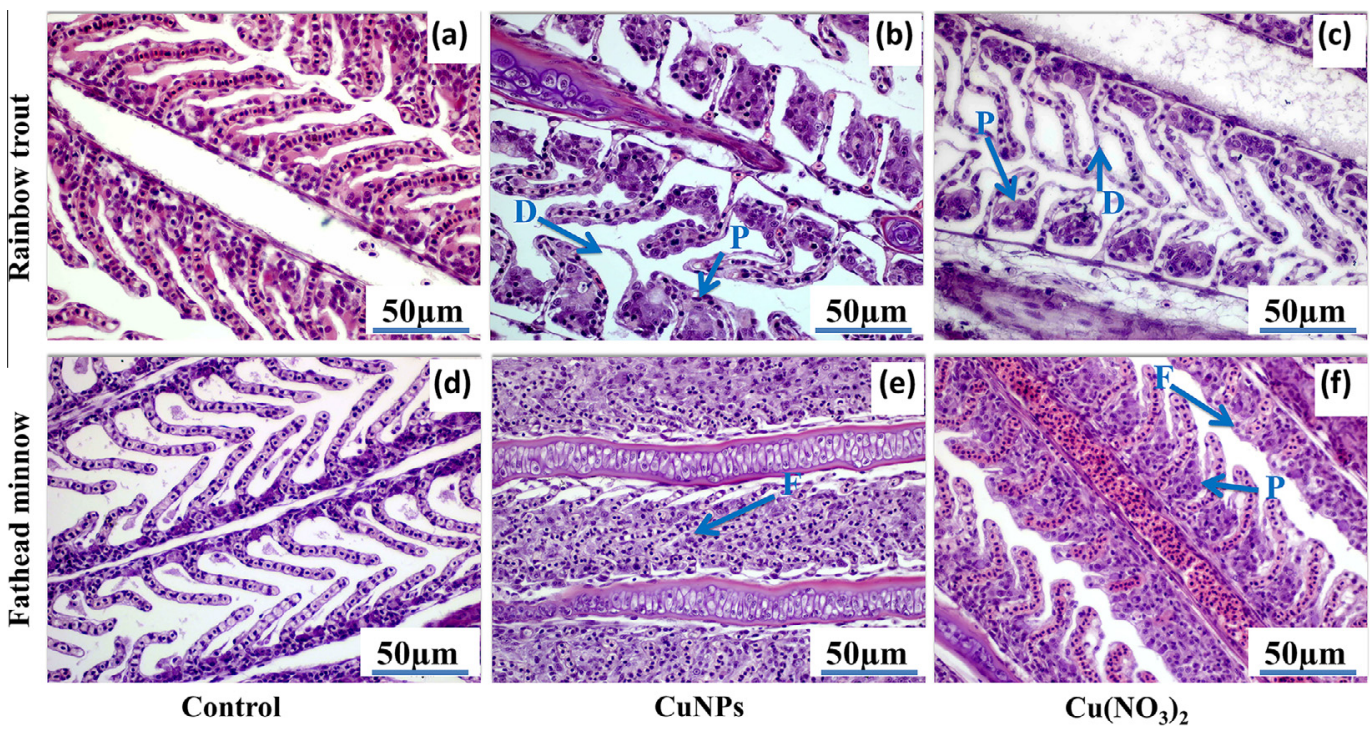

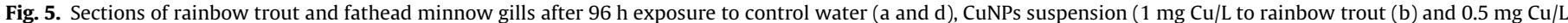

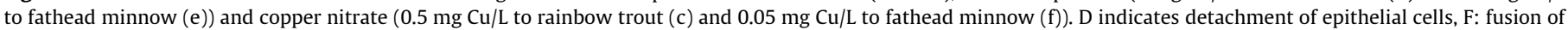
secondary lamellae, P: proliferation of epithelial cells. Sectioned were stained with haematoxylin and eosin.

tissues, which included both proliferation and detachment of epithelial cells at the base of secondary lamellae (Fig. 5b and c). In fathead minnows, fusion of secondary lamellae occurred in the gills for exposure to $0.5 \mathrm{mg} \mathrm{Cu} / \mathrm{L}(96 \mathrm{~h}$ ) (Fig. 5e) and both fusion and proliferation of epithelial cells in the gills for exposure to $0.05 \mathrm{mg} \mathrm{Cu} / \mathrm{L}$ (Fig. 5f).
SEM indicated a difference in the ultrastructure of the lamellae of rainbow trout and fathead minnow exposed to the CuNPs suspension and $\mathrm{Cu}\left(\mathrm{NO}_{3}\right)_{2}$ compared with controls (Fig. 6). There was a reduced prominence in the micro-ridging of the cell surface of the pavement cells (PVC) of the gill filaments (indicated by blue arrows). This effect was especially pronounced in the fathead 


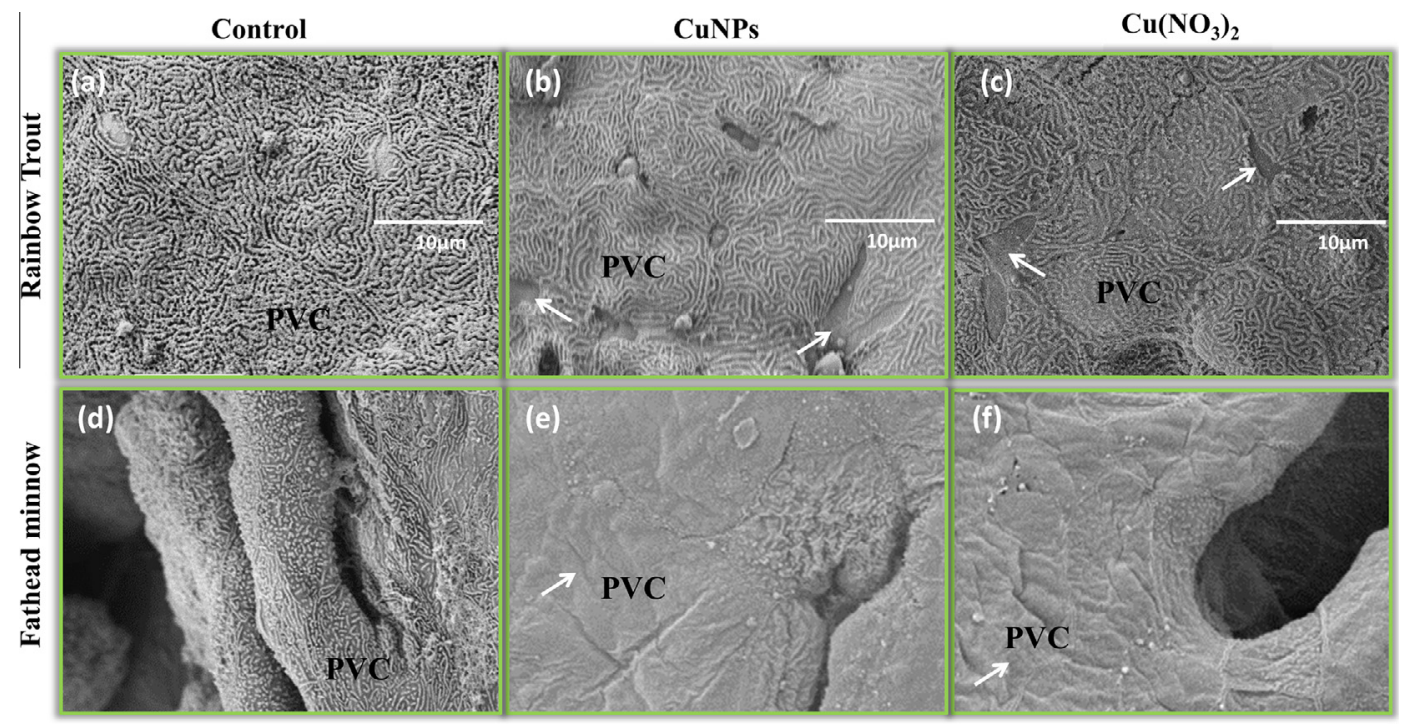

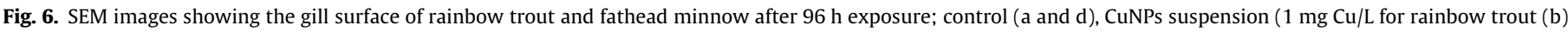

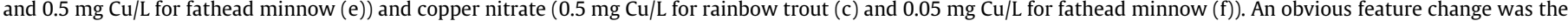
reduction in the presence/prominence of microridges on the surface of pavement cells (PVC) in the CuNP/copper nitrate treated fish.

minnow exposed to the CuNPs suspension and $\mathrm{Cu}\left(\mathrm{NO}_{3}\right)_{2}$ where there was an absence of microridges on the PVCs (96 h).

\section{Discussion}

\subsection{Fate of CuNPs in test media}

The particle characterization data illustrated that the CuNPs were polydispersed in the exposure water as nanostructured aggregates. Nanostructured aggregates of $\mathrm{Cu}$ will have a different surface area compared with monodispersed NPs and thus a different surface reactivity. Thus, the biological effects of the CuNPs suspension cannot be related directly to the CuNPs in their pristine state. This will hold true for almost all nanomaterials in aqueous test systems and even more so as they enter natural waters, where natural humics, polysaccharides and other organic materials will further affect their form, fate and behavior (Quik, 2013).

In the exposures conducted, CuNPs formed larger aggregates at $26{ }^{\circ} \mathrm{C}$ than at $15^{\circ} \mathrm{C}$ in the same test water, indicating water temperature is an important parameter affecting the aggregation of NPs in water. Elevated temperature can decrease the solution viscosity and lower the interfacial energy barrier, which can result in larger sizes of NP aggregates (Chen, 2012). We also show that the percentage of ion release was considerably higher for CuNPs at a water temperature of $26^{\circ} \mathrm{C}$ compared with at $15^{\circ} \mathrm{C}$. This supports previous reports that temperature is an important factor affecting the dissolution of metallic NPs (Liu and Hurt, 2010; Meulenkamp, 1998) and clearly has an important bearing when considering metal NP toxicology.

In our exposure studies we found the percentage of ion release from CuNPs was between $7 \%$ and $15 \%$ at $15{ }^{\circ} \mathrm{C}$ and $25 \pm 3 \%$ at $26^{\circ} \mathrm{C}$ water after $24 \mathrm{~h}$ incubation in water. At $24 \mathrm{~h}$, the ion release from copper-based NPs has been shown previously to range from $0.1 \%$ (Griffitt et al., 2008, 2007) to 36\% (Hua et al., 2014). Although differences in water chemistry and the particles themselves might account partially for the difference reported across the studies on the amount of ions released, there may be other experimental differences accounting for, or at least contributing to, these differences, including differences in centrifugation speed and whether or not temperature was controlled during centrifugation of water the samples when separating particle and ions. Collectively, these data emphasise the need for provide full particle characterization data for exposures in aqueous to allow for appropriate interpretations of biological effects data.

An important parameter reflecting the stability of CuNPs suspension is the zeta potential. According to the DLVO theory, a suspension with a zeta potential higher than $+30 \mathrm{mV}$ or lower than $-30 \mathrm{mV}$ is considered as stable suspensions (Derjaguin and Landau, 1941; Verwey and Overbeek, 1948). Zeta potential measurements for the CuNPs in the synthesised water in the test on fish here showed that the NPs aggregates were not stable. Aggregation, dissolution and re-dispersion of these aggregates could be expected over time on the basis of these theoretical considerations.

\subsection{Acute toxicity of the CuNPs suspension}

Our results show that the CuNPs suspension and copper nitrate were toxic to all three fish species studied (De Boeck et al., 2004; Griffitt et al., 2008; Zhao et al., 2011). The $96 \mathrm{~h} \mathrm{LC}_{50}$ value of copper ions in rainbow trout $(0.24 \pm 0.03 \mathrm{mg} / \mathrm{L})$ is comparable to the $96 \mathrm{~h}$ $\mathrm{LC}_{50}$ values reported previously for similar exposure conditions (De Boeck et al., 2004; Hale, 1977). Similarly, the copper 96 h LC 50 value for fathead minnow was also comparable to that reported in previous studies for this species for similar exposure conditions (Pickering and Henderson 1966; Tarzwell and Henderson 1960). It should be emphasized that body mass can significantly affect the threshold response to copper (Howarth and Sprague, 1978). As an example, the $96 \mathrm{~h} \mathrm{LC}_{50}$ for copper ions in rainbow trout is significantly higher (less sensitive) in larger $(20.3 \pm 4.5 \mathrm{~g})$ versus smaller (less than $1 \mathrm{~g}$ ) fish (Besser et al., 2007; Calfee et al., 2014).

Values for $\mathrm{LC}_{50}$ of CuNPs suspension in our studies $(48 \mathrm{~h})$ on zebrafish were lower (i.e. the CuNPs suspension was more toxic) compared with the studies conducted by Griffitt et al. (2007, 2008) ( $48 \mathrm{~h} \mathrm{LC}_{50}$ of $0.40 \pm 0.00 \mathrm{mg} \mathrm{Cu} / \mathrm{L}$, versus $1.5 \mathrm{mg} \mathrm{Cu} / \mathrm{L}$ for $80 \mathrm{~nm}$ CuNPs suspension and $0.94 \mathrm{mg} \mathrm{Cu} / \mathrm{L}$ for $27 \mathrm{~nm}$ CuNPs suspension). These relatively small differences may be accounted for by differences in water qualities parameters of differences due to the different CuNPs particles used in the different exposures. In a further study on CuNPs (the same $50 \mathrm{~nm}$ used in our study), the $96 \mathrm{~h} \mathrm{LC}_{50}$ for exposed zebrafish embryos (Hua et al., 2014) was $1.9 \mathrm{mg} \mathrm{Cu} / \mathrm{L}$, approximately ten times higher (i.e. less toxic) than 
we found for juvenile zebrafish. These findings suggest that life stage of the fish can have a significant bearing on sensitivity to the toxicity of CuNPs and this need to be considered in any comparison of studies conducted and in the risk assessment process for CuNPs.

\subsection{Toxicity - copper ions and particles}

CuNPs tend to both release metal ions and form aggregates in the water phase. Most studies have suggested that the toxicity of metallic NPs suspensions is attributed to release of metal ions (Griffitt et al., 2009; Hoheisel et al., 2012). Our findings support this for CuNPs, where we found that soluble copper was a main driver for the toxicological effect for CuNPs for all the tested fish species. Previous research has shown that gills are the primary target of copper ions in fish (Evans, 1987) causing a reduced ability for ammonia excretion and sodium uptake (Zimmer et al., 2014). Ultimately, mortality due to copper ion exposure in fish occurs as a consequence of disrupted osmoregulation (Grosell et al., 2007).

Nevertheless, several studies on metal oxide NP more widely have indicated that the release of metal ions into the test medium cannot fully account for the toxicity of metal NPs suspensions. Examples of this include for $\mathrm{Al}_{2} \mathrm{O}_{3}$ NPs (with a mean size of $60 \mathrm{~nm}$ ) and $\mathrm{TiO}_{2} \mathrm{NPs}$ (with a mean size of $50 \mathrm{~nm}$ ) where the $24 \mathrm{~h}$ $\mathrm{LC}_{50}$ in nematode Caenorhabditis elegans were significantly lower (the substance was more toxic) than the corresponding bulk materials, indicating the extra particle effect of these NPs (Wang et al., 2009). Our results also indicate that the CuNPs particles themselves appear to account for some of the toxicity of the CuNPs suspension in fathead minnow. The toxic mechanism of nano aggregates is not known although again, the gill is believed to be a primary target organ for such these NP effects (Griffitt et al., 2007). In a study on the toxicity of $\mathrm{TiO}_{2} \mathrm{NPs}$ (with a mean size of $21 \mathrm{~nm}$ ) a 14 day exposure of rainbow trout induced a significantly higher incidence of hyperplasia in the gill compared with the same concentration of bulk $\mathrm{TiO}_{2}$ (Boyle et al., 2013). It is believed that NPs may also enter into the cardiovascular system through the damaged gills where they can induce damage to other internal organs, although this is largely speculation with little data to substantiate this (Handy et al., 2008). Contrasting with the findings for fathead minnow there was no particle effects apparent for our studies on zebrafish and rainbow trout. We can speculate that these differences in sensitivity between specie may relate to differences in their physiology (Eyckmans et al., 2011; Grosell et al., 2007), but this will likely only be elucidate when the precise toxic mechanism of NPs and nanostructure particles are better established.

\subsection{Relative sensitivities of different fish species to CuNPs suspension}

The sensitivity of the tested fish species to the CuNPs suspension varied (see Supplementary Information 3). The most sensitive species tested was the zebrafish and the least sensitive the rainbow trout. The difference seen in sensitivity to the CuNPs between the three fish species to the CuNP, however, may relate to the conditions of the exposures. Temperature may have been the dominant factor affecting the difference in the relative toxicity to the CuNPs between the rainbow trout (incubated at $15^{\circ} \mathrm{C}$ ) and the cyprinid fish (incubated at $26^{\circ} \mathrm{C}$ ), as we clearly show that there was a higher rate of dissolution at the higher incubation temperature and thus the availability of more copper ions in the exposure water for the fathead minnow and zebrafish. As copper ions contributed significantly (is the dominant factor) in the toxicity of CuNPs suspension, this likely describes why the rainbow trout appeared to be somewhat less sensitive to the effects of CuNPs suspension.
There are also differences in toxicity that relate to differences in the intrinsic physiology between salmonid and cyprinid fish relevant to handling copper ions (Heath, 1995). Previous research showed copper tends to have a higher accumulation rate in liver but a lower residence and accumulation in kidney in rainbow trout (salmonidae) compared to gibel carp (cyprinidae) (De Boeck et al., 2004). Another study has shown that rainbow trout have a different defense mechanism against copper exposure compare to cyprinidae species, specifically the common carp (Cyprinus carpio) and gibel carp (Carassius auratus gibelio) (Eyckmans et al., 2011). Rainbow trout relies mainly on glutathione while cyprinidae species rely more on metallothionein in combination with anti-oxidant enzymes to detoxify the effect of copper ions (Eyckmans et al., 2011). This knowledge does not allow us to identify why the zebrafish was the most sensitive to the effects of CuNPs, but it does serve to illustrate that differences in physiology are likely to be a key factors contributing to differences in sensitivity of fish species to a CuNPs suspension.

Further general features of the fish and their exposure conditions could also have had a bearing on the findings. For example, a previous study showed that rainbow trout with a body weight of $10 \mathrm{~g}$ was 2.5 times less sensitive to copper ions compared with $0.7 \mathrm{~g}$ rainbow trout (Howarth and Sprague, 1978). Smaller organisms tend to have a larger mass-specific metabolic rate than larger-bodied organisms and this can be applied across species (Brown et al., 2004; Gillooly et al., 2001; Peters, 1986). Also, organisms living in warm environments tend to have higher metabolic rates than organisms living in a colder environment (Brown et al., 2004). In this study, zebrafish and fathead minnow had a lighter body weight and was exposed to the CuNPs suspension and copper ions under a higher temperature compared with juvenile trout. A higher metabolic rate in smaller fish (zebrafish and fathead minnow) will result in a higher uptake rate of toxicants from the environment (Brown et al., 2004).

To sum up, what is clear from the data presented is that for any comparison and extrapolation between species for assessing effects of metal based NPs that can undergo dissolution, considerations of the exposure conditions and the physiological attributes of testing species as well as how they differ between the test systems is critical.

\subsection{Gill histopathology}

In freshwater fish, that do not drink, the gills are subjected to an enormous flux of water and therefore constantly exposed to the array of toxicants present in the water column. Gills are not only the primary site facilitating respiration for the majority of fish species, but also the principal site for regulating body fluid $\mathrm{pH}$ and for nitrogenous waste excretion (Evans et al., 2005). The high surface area of the epithelium in the gills makes them further susceptible to effects of aquatic toxicants (Evans, 1987). Here we observed that both the CuNPs suspension and copper ions induced tissue damage rapidly to the gill of rainbow trout and fathead minnow (within 4 days), which is in agreement with previous findings (Xiong et al., 2011; Zhao et al., 2011). Morphological alteration of gills included detachment and proliferation of epithelial cells at the base of secondary lamellae and fusion of secondary lamellae that may affect osmoregulatory and respiratory functions of the fish gill. Some of the effects seen in the gills were similar between the rainbow trout and fathead minnow, however there were also differences seen, suggesting some species specific effects on gill function.

The SEM observations of the exposed gills revealed that the CuNPs suspension and $\mathrm{Cu}\left(\mathrm{NO}_{3}\right)_{2}$ caused a reduction in the microridges on pavement cells. The main function of microridges is to increase the functional surface area of the epithelium (Evans 
et al., 2005) and to hold mucus to protect the epithelial layer (Sperry and Wassersug, 1976).The reduction of microridges directly decreases the contact area with the external medium and therefore reduces the exchange between gill and water. Furthermore, published studies have shown that mucus can trap NPs (Smith et al., 2007) and thus helps to reduce any damage that might otherwise be caused by these NPs (Handy et al., 2008). The reduction in the microridges on the PVC therefore by the copper materials has functional significance for the health of the exposed fish.

\subsection{Environmental relevance}

Currently little has been reported regarding the concentration of CuNPs in the environment. The predicted environmental concentration of CuNPs suspension in some receiving waters is $0.06 \mathrm{mg} \mathrm{Cu} / \mathrm{L}$ with a 95\% confidence interval of $0.01-0.92 \mathrm{mg}$ $\mathrm{Cu} / \mathrm{L}$ (Chio et al., 2012). Predicted concentrations of CuNPs in some freshwater aquatic systems may exceed the LOEC values of CuNPs reported and therefore they may pose risk to some fish species in natural systems. It is becoming increasingly recognised however that factors, such as organic substances (Quik, 2013), can strongly influence the fate and toxicity of NPs in the environment, often reducing their toxic capacity. These factors are important to consider in the evaluation of the potential risk of CuNPs in the environment. The present work shows that the physical environment (i.e. water temperature) has a fundamental bearing on CuNPs toxicity in fish, but differences in intrinsic physiology between fish species may also play a role in explaining differences in their sensitivity to CuNPs toxicity. Our findings illustrate that extrapolations of toxicity of NPs across different species, even under standardized test conditions requires caution and illustrates the need for reporting explicitly details of the exposure conditions to enable comparison of effects data for metal/metal oxide based materials in aqueous media, especially those that undergo dissolution.

\section{Conflict of interest}

The authors declare that they have no conflict of interest.

\section{Acknowledgements}

The work conducted at Exeter University was sponsored by the European Union-funded infrastructure for Quality in nanomaterials safety testing (QualityNano), Grant Agreement No. FP7-262163, held by Tamara S. Galloway and Charles R. Tyler, the authors thank Janice Shears, Rhys Goodhead, Victoria Jennings, Anke Lange, Darren Rowe, Gregory Paull, Peter Splatt and Massimo Micaroni for their kind assistance. Lan Song is sponsored by the Environmental ChemOinformatics Marie Curie Initial Training Network (ECO-ITN) within the seventh research framework programme of the European Union (238701).

\section{Appendix A. Supplementary material}

Supplementary data associated with this article can be found, in the online version, at http://dx.doi.org/10.1016/j.chemosphere. 2015.06.021.

\section{References}

Al-Bairuty, G.A., Shaw, B.J., Handy, R.D., Henry, T.B., 2013. Histopathological effects of waterborne copper nanoparticles and copper sulphate on the organs of rainbow trout (Oncorhynchus mykiss). Aquat. Toxicol. 126, 104-115.

Baalousha, M., Manciulea, A., Cumberland, S., Kendall, K., Lead, J.R., 2008. Aggregation and surface properties of iron oxide nanoparticles: influence of $\mathrm{pH}$ and natural organic matter. Environ. Toxicol. Chem. 27, 1875-1882.
Backhaus, T., Scholze, M., Grimme, L., 2000. The single substance and mixture toxicity of quinolones to the bioluminescent bacterium Vibrio fischeri. Aquat. Toxicol. 49, 49-61.

Besser, J.M., Mebane, C.A., Mount, D.R., Ivey, C.D., Kunz, J.L., Greer, I.E., May, T.W. Ingersoll, C.G., 2007. Sensitivity of mottled sculpins (Cottus bairdi) and rainbow trout (Onchorhynchus mykiss) to acute and chronic toxicity of cadmium, copper, and zinc. Environ. Toxicol. Chem. 26, 1657-1665.

Black, J.G., Reichelt-Brushett, A.J., Clark, M.W., 2015. The effect of copper and temperature on juveniles of the eurybathic brittle star Amphipholis squamata exploring responses related to motility and the water vascular system. Chemosphere 124, 32-39.

Boyle, D., Al-Bairuty, G.A., Ramsden, C.S., Sloman, K.A., Henry, T.B., Handy, R.D., 2013. Subtle alterations in swimming speed distributions of rainbow trout exposed to titanium dioxide nanoparticles are associated with gill rather than brain injury. Aquat. Toxicol. 126, 116-127.

Brown, J.H., Gillooly, J.F., Allen, A.P., Savage, V.M., West, G.B., 2004. Toward a metabolic theory of ecology. Ecology 85, 1771-1789.

Calfee, R.D., Little, E.E., Puglis, H.J., Scott, E., Brumbaugh, W.G., Mebane, C.A., 2014 Acute sensitivity of white sturgeon (Acipenser transmontanus) and rainbow trout (Oncorhynchus mykiss) to copper, cadmium, or zinc in water-only laboratory exposures. Environ. Toxicol. Chem. 33, 2259-2272.

Chen, Y., 2012. Temperature effect on the aggregation kinetics of $\mathrm{CeO}_{2}$ nanoparticles in monovalent and divalent electrolytes. J. Environ. Anal. Toxicol.

Chen, H., Chen, Y., Zheng, X., Li, X., Luo, J., 2014. How does the entering of copper nanoparticles into biological wastewater treatment system affect sludge treatment for VFA production. Water Res. 63, 125-134.

Chio, C.-P., Chen, W.-Y., Chou, W.-C., Hsieh, N.-H., Ling, M.-P., Liao, C.-M., 2012 Assessing the potential risks to zebrafish posed by environmentally relevant copper and silver nanoparticles. Sci. Total Environ. 420, 111-118.

De Boeck, G., Meeus, W., Coen, W.D., Blust, R., 2004. Tissue-specific Cu bioaccumulation patterns and differences in sensitivity to waterborne $\mathrm{Cu}$ in three freshwater fish: rainbow trout (Oncorhynchus mykiss), common carp (Cyprinus carpio), and gibel carp (Carassius auratus gibelio). Aquat. Toxicol. 70, 179-188.

Derjaguin, B., Landau, L., 1941. Theory of the stability of strongly charged lyophobic sols and of the adhesion of strongly charged particles in solutions of electrolytes. Acta Physico Chemica URSS 14, 633.

EPA US, 1986. Fish life-cycle toxicity tests. EPA 540/9-86-137. Washington, DC, U.S Environment Protection Agency.

Evans, D.H. 1987. The fish gill: site of action and model for toxic effects of environmental pollutants. Environ. Health Perspect. 71, 47.

Evans, D.H., Piermarini, P.M., Choe, K.P., 2005. The multifunctional fish gill: dominant site of gas exchange, osmoregulation, acid-base regulation, and excretion of nitrogenous waste. Physiol. Rev. 85, 97-177.

Eyckmans, M., Celis, N., Horemans, N., Blust, R., De Boeck, G., 2011. Exposure to waterborne copper reveals differences in oxidative stress response in three freshwater fish species. Aquat. Toxicol. 103, 112-120.

Ganesh, R., Smeraldi, J., Hosseini, T., Khatib, L., Olson, B.H., Rosso, D., 2010. Evaluation of nanocopper removal and toxicity in municipal wastewaters. Environ. Sci. Technol. 44, 7808-7813.

Gillooly, J.F., Brown, J.H., West, G.B., Savage, V.M., Charnov, E.L., 2001. Effects of size and temperature on metabolic rate. Science 293, 2248-2251.

Griffitt, R.J., Weil, R., Hyndman, K.A., Denslow, N.D., Powers, K., Taylor, D., Barber D.S., 2007. Exposure to copper nanoparticles causes gill injury and acute lethality in zebrafish (Danio rerio). Environ. Sci. Technol. 41, 8178-8186.

Griffitt, R.J., Luo, J., Gao, J., Bonzongo, J.-C., Barber, D.S., 2008. Effects of particle composition and species on toxicity of metallic nanomaterials in aquatic organisms. Environ. Toxicol. Chem. 27, 1972-1978.

Griffitt, R.J., Hyndman, K., Denslow, N.D., Barber, D.S., 2009. Comparison of molecular and histological changes in zebrafish gills exposed to metallic nanoparticles. Toxicol. Sci. 107, 404-415.

Grillo, R., Rosa, A.H., Fraceto, L.F., 2015. Engineered nanoparticles and organic matter: a review of the state-of-the-art. Chemosphere 119, 608-619.

Grosell, M., Blanchard, J., Brix, K.V., Gerdes, R., 2007. Physiology is pivotal for interactions between salinity and acute copper toxicity to fish and invertebrates. Aquat. Toxicol. 84, 162-172.

Hale, J.G., 1977. Toxicity of metal mining wastes. Bull. Environ. Contam. Toxicol. 17, $66-73$

Han, K.I., Kang, S.W., Kim, J., Kang, Y.S., 2011. Effect of ionic liquids on dissociation of copper flake into copper nanoparticles and its application to facilitated olefin transport membranes. J. Membr. Sci. 374, 43-48.

Handy, R.D., Owen, R., Valsami-Jones, E., 2008. The ecotoxicology of nanoparticles and nanomaterials: current status, knowledge gaps, challenges, and future needs. Ecotoxicology 17, 315-325.

Hatamie, A., Zargar, B., Jalali, A., 2014. Copper nanoparticles: a new colorimetric probe for quick, naked-eye detection of sulfide ions in water samples. Talanta 121, 234-238.

Heath, AG., 1995. Water Pollution and Fish Physiology. CRC press.

Hoheisel, S.M., Diamond, S., Mount, D., 2012. Comparison of nanosilver and ionic silver toxicity in Daphnia magna and Pimephales promelas. Environ. Toxicol. Chem. 31, 2557-2563.

Howarth, R.S., Sprague, J.B., 1978. Copper lethality to rainbow trout in waters of various hardness and $\mathrm{pH}$. Water Res. 12, 455-462.

Hua, J., Vijver, M.G., Ahmad, F., Richardson, M.K., Peijnenburg, W.J.G.M., 2014 Toxicity of different-sized copper nano- and submicron particles and their shed copper ions to zebrafish embryos. Environ. Toxicol. Chem. 33, 1774-1782. 
Kida, T., Oka, T., Nagano, M., Ishiwata, Y., Zheng, X.G., 2007. Synthesis and application of stable copper oxide nanoparticle suspensions for nanoparticulate film fabrication. J. Am. Ceram. Soc. 90, 107-110.

Kim, D.-K., Yoo, S.M., Park, T.J., Yoshikawa, H., Tamiya, E., Park, J.Y., Lee, S.Y., 2011. Plasmonic properties of the multispot copper-capped nanoparticle array chip and its application to optical biosensors for pathogen detection of multiplex DNAs. Anal. Chem. 83, 6215-6222.

Kong, X., Jiang, H., Wang, S., Wu, X., Fei, W., Li, L., Nie, G., Li, X., 2013. Effects of copper exposure on the hatching status and antioxidant defense at different developmental stages of embryos and larvae of goldfish Carassius auratus. Chemosphere 92, 1458-1464.

Kubota, S., Morioka, T., Takesue, M., Hayashi, H., Watanabe, M., Smith Jr., R.L., 2014 Continuous supercritical hydrothermal synthesis of dispersible zero-valent copper nanoparticles for ink applications in printed electronics. J. Supercrit. Fluids 86, 33-40.

Lee, J.H., Hong, J., Kim, J.H., Song, D., Kang, Y.S., Kang, S.W., 2014. Surface tuned copper nanoparticles by 1 -methyl-3-octylimidazolium tetrafluoroborate and its applications to facilitated $\mathrm{CO}_{2}$ transport. Chem. Eng. J. 235, 252-256.

Li, Y. Fu, J., Chen, R., Huang, M. Gao, B., Huo, K., Wang L. Chu, P.K, 2014. Core-shell $\mathrm{TiC} / \mathrm{C}$ nanofiber arrays decorated with copper nanoparticles for high performance non-enzymatic glucose sensing. Sens. Actuators B: Chem. 192, 474-479.

Liu, J., Hurt, R.H., 2010. Ion release kinetics and particle persistence in aqueous nano-silver colloids. Environ. Sci. Technol. 44, 2169-2175.

Lowry, G.V., Gregory, K.B., Apte, S.C., Lead, J.R., 2012. Transformations of nanomaterials in the environment. Environ. Sci. Technol. 46, 6893-6899.

Meulenkamp, E.A., 1998. Synthesis and growth of ZnO nanoparticles. J. Phys. Chem. B 102, 5566-5572.

OECD, 1992. OECD 203 guideline for testing of chemicals: Fish, Acute Toxicity Test. Office H, 1996. Code of Practice for the Humane Killing of Animals under Schedule 1 to the Animals (Scientific Procedures) Act 1986: HMSO, London.

Paull, G.C., Van Look, K.J.W., Santos, E.M., Filby, A.L., Gray, D.M., Nash, J.P., Tyler, C.R. 2008. Variability in measures of reproductive success in laboratory-kept colonies of zebrafish and implications for studies addressing population-level effects of environmental chemicals. Aquat. Toxicol. 87, 115-126.
Peters, RH., 1986. The Ecological Implications of Body Size. Cambridge University Press.

Pickering, Q.H., Henderson, C., 1966. The acute toxicity of some heavy metals to different species of warmwater fishes. Air Water Pollut. 10, 453-463.

Quik, J.T., 2013. Fate of nanoparticles in the aquatic environment. Fate of nanoparticles in the aquatic environment. Removal of engineered nanomaterials from the water phase under environmental conditions. PhD thesis, Radboud University Nijmegen, The Netherlands.

Smith, C.J., Shaw, B.J., Handy, R.D., 2007. Toxicity of single walled carbon nanotubes to rainbow trout (Oncorhynchus mykiss): respiratory toxicity, organ pathologies, and other physiological effects. Aquat. Toxicol. 82, 94-109.

Song L., Connolly, M., Fernández-Cruz, M.L. Vijver, M.G., Fernández, M., Conde, E. de Snoo, G.R., Peijnenburg, W.J., Navas, J.M., 2014. Species-specific toxicity of copper nanoparticles among mammalian and piscine cell lines. Nanotoxicology 8, 383-393.

Sperry, D.G., Wassersug, R.J., 1976. A proposed function for microridges on epithelial cells. Anat. Rec. 185, 253-257.

Tarzwell, C.M., Henderson, C., 1960. Toxicity of less common metals to fishes. Ind. Wastes 5, 12.

Verwey, E.J.W., Overbeek, J.T.G., 1948. Theory of the Stability of Lyophobic Colloids. Elsevier, Amsterdam.

Wang, H., Wick, R.L., Xing, B., 2009. Toxicity of nanoparticulate and bulk $\mathrm{ZnO}, \mathrm{Al}_{2} \mathrm{O}_{3}$ and $\mathrm{TiO}_{2}$ to the nematode Caenorhabditis elegans. Environ. Pollut. 157, 1171-1177.

Wang, T., Long, X., Cheng, Y., Liu, Z., Yan, S., 2014. The potential toxicity of copper nanoparticles and copper sulphate on juvenile Epinephelus coioides. Aquat. Toxicol. 152, 96-104.

Xiong, D., Fang, T., Yu, L., Sima, X., Zhu, W., 2011. Effects of nano-scale $\mathrm{TiO}_{2}$, ZnO and their bulk counterparts on zebrafish: acute toxicity, oxidative stress and oxidative damage. Sci. Total Environ. 409, 1444-1452.

Zhao, J., Wang, Z., Liu, X., Xie, X., Zhang, K., Xing, B., 2011. Distribution of CuO nanoparticles in juvenile carp Cyprinus carpio and their potential toxicity. J. Hazard. Mater. 197, 304-310.

Zimmer, A.M., Brauner, C.J. Wood, C.M., 2014. Exposure to waterborne Cu inhibits cutaneous $\mathrm{Na}^{+}$uptake in post-hatch larval rainbow trout (Oncorhynchus mykiss). Aquat. Toxicol. 150, 151-158. 